\title{
The Association Between Maternal Self-confidence and Functional Status in Primiparous Women During Postpartum Period, 2015-2016
}

\author{
Fahimeh Sehati Shafaie ${ }^{1}$, Mojgan Mirghafourvand ${ }^{1}$, Marzieh Bagherinia $^{{ }^{*}}$
}

\begin{abstract}
Objectives: Transition to motherhood, is a challenging and stressful process in postpartum period as the women not only face new tasks associated with the maternal role but also the dramatic changes in their bodies. This study was performed with the aim to determine the relationship between maternal self-confidence and functional status in postpartum period.

Materials and Methods: This cross-sectional study was conducted on 136 primiparous women at 2 weeks postpartum who were referred to 25 health centers of Tabriz, from December 2015 to April 2016. Data were collected using the socio-demographic characteristics questionnaire, Lips Maternal Self-confidence Score (LMSCS) and Inventory of Functional Status After Childbirth (IFSAC). The statistical tests including Pearson correlation, independent sample $t$ test, one-way analysis of variance (ANOVA) and general linear model were used for data analysis through SPSS v. 21. The significance level was considered as $P<0.05$.

Results: The mean (SD) of total functional status scores was $2.2 \pm 0.4$, with achievable scores ranging from 1 to 4 and maternal self-confidence scores was $105.6 \pm 11.2$, with achievable scores ranging from 24 to 144 . Between functional status and maternal selfconfidence there was significantly positive and strong correlations $(P=0.001, r=0.271)$.

Conclusion: The results show that maternal self-confidence has a positive effect on functional status in postpartum period and increased self-confidence leads to improved functional status.

Keywords: Postpartum period, Self-concept, Women
\end{abstract}

\section{Introduction}

The postpartum period is a time of important transition for parents, children and their families physiologically, emotionally and socially (1). Many women do not completely recover to their pre-pregnancy condition within 6 weeks after delivery, which is considered the postpartum period (2). Transition to motherhood, is a challenging and stressful process in postpartum period as the women not only face new tasks associated with the maternal role but also the dramatic changes in their bodies (3). Women are concerned about their needs in the postpartum period even in a normal pregnancy and delivery (4).

Maternal self-confidence is defined as the mother's perception of her own ability to take care of the infant and understanding his/her needs (5). Maternal selfconfidence, as an important variable in accepting the maternal role, can facilitate maternal role development, improve neonatal outcomes, and promote infant nurturing and development. Higher confidence causes the mother to feel more complete in her maternal role. It also plays a critical role in influencing maternal competence and parenting stress, so that maternal competence can mitigate parental stress (6-8). If becoming a mother in the postpartum period goes well, the mother can expand her self-confidence in her maternal role, loving the newborn, and accepting her new personality and role as a mother (9). Lack of maternal knowledge, experience and skills reduces self-confidence (10). If the mother lacks self-confidence in the care for her infant in the early postpartum period, it may become a negative motherhood experience, causing her to fail properly in taking care of her newborn (11). This negative feeling can affect the bonding between the mother and the baby after birth (12).

Postpartum recovery is often focused primarily on resumption of physical abilities including the healing of the reproductive tract, and the complete functioning ability after delivery is overlooked (13). Return to full functional status takes longer time in most women than physical recovery and is often achieved gradually over a long period (14). Functional status after childbirth is defined as a multidimensional concept that involves personal care, infant care, family care, and social and occupational activities (15). Recovery to pre-pregnancy functional status is achieved when the mother accepts her maternal role and responsibilities and, by accepting the baby, reorganizes her life according to these responsibilities (14). In addition, recovery to the functional status refers to the resumption of the roles that women do before pregnancy (16).

Maternal self-confidence is a determining factor in anxiety and stress related to infant care in the postpartum 
period (17). In addition, assessment of women's functional status in the postpartum period can provide information about the mother's competence in her maternal role. It can also be useful in screening for postpartum depression (15). Functional status of women is likely to be associated with neonatal outcomes (18).

According to the researcher's investigations, no studies have been conducted on the relationship between the maternal self-confidence and functional status of the postpartum in Iran. Moreover, few studies have examined this subject at international. Given the importance of improvement in postpartum functional status of mothers and infants and considering the fact that mothers are currently provided more with physical healthcare services in the postpartum period, it will be helpful to identify the factors influencing the quicker improvement in the functional status and make service providers in the health care system acquainted with them. Therefore, the aim of the present study was to determine the relationship between maternal self-confidence and the functional status among primiparous women in the postpartum period.

\section{Materials and Methods}

This cross-sectional study was performed on 136 primiparous women at 2 weeks postpartum who were referred to 25 health centers of Tabriz. Inclusion criteria included primiparous women, age of 18-35, singleton pregnancy, term birth (37-42 weeks), secondary school or higher education, physical health according to the mother, and willingness to participate in the study. Exclusion criteria included adverse event during the 3 months before the start of the study (death or serious illness of close relatives), history of mental illness and depression in women before pregnancy and during pregnancy according to participants, hospitalization of newborn due to illness in the postpartum period, abnormalities in the newborn, newborn's death, and unwillingness to continue to participate in the study while completing the questionnaire.

The current study was taken from a research work investigating the effect of training package on functional status and self-confidence in primiparous women in the postpartum period. The sample size was calculated using G-Power software and based on a study by Jaafarnejad et al (19) on maternal self-confidence and a study by Mirghafourvand et al (20) on functional status. The final sample size was calculated as 136 based on the variable of self-confidence, and by taking $\mathrm{m}_{1}=107.2$, $\mathrm{SD}_{1}=7.9, \mathrm{~m}_{2}=113.1, \mathrm{SD}_{2}=11.5, \alpha=0.05$, Power $=95 \%$ and considering a $10 \%$ possible dropout.

Sampling was conducted after obtaining approval from the Ethics Committee of Research and Technology Deputy of Tabriz University of Medical Sciences from December 2015 to April 2016. For sampling, one-third of health centers in Tabriz (25 centers) were randomly selected, using computer-generated random numbers (https://www.random.org), and the appropriate sample size was calculated proportional to the population of each health center and base, using proportional to size sample. Then, mothers who were under coverage of the centers in the 2 weeks after childbirth were enlisted by referring to their health records. The researcher, then called the cases and provided them with adequate explanations about the study and invited them to participate. In addition, they were provided with the researcher's telephone number for coordinating their presence in the health centers after delivery. Information on the study, methodology and confidentiality matters was provided to participants by researcher. Then, they were voluntarily included in the study after obtaining their informed consent.

Data was collected using demographic, maternal self-confidence, and functional status questionnaires. The researcher-designed demographic questionnaire included items on maternal age, type of delivery, spouse and mother's education, spouse and mother's occupation, income, sex of newborn, wanted or unwanted pregnancy, and marital satisfaction. Its validity was confirmed by 8 university faculty members. Information on maternal self-confidence after delivery was collected through Lips Maternal Self-confidence Score (LMSCS). This questionnaire was originally designed by Lips \& Bloom in 1993 to evaluate maternal postpartum self-confidence; however, it was not published at the time. Then, in a study by Reck et al in 2003-2005 the German translation of the questionnaire was used. The questionnaire contains 24 self-report positive-negative items. Each item is scored using a 6-point Likert scale from strongly agree to strongly disagree. The total score ranges from 24 to 144 , while higher scores are indicative of higher confidence levels (21). The questionnaire was validated in Iran by Jaafarnejad et al and its Cronbach alpha was reported as $a=0.84$ (19).

Data on postpartum functional status was collected using the Inventory of Functional Status After Childbirth (IFSAC). The questionnaire was initially designed by Fawcett et al and contains 36 self-report items to assess the ability of mothers to assume new responsibilities based on 5 areas, namely, infant care, self-care, household, social and community, and occupational activities. Items in self care and occupational activities subscales are rated on a 4-point scale, with $1=$ never, $2=$ sometimes, $3=$ most of the time, and $4=$ all the time. In the other subscales, the items are rated on a 4 -point scale, with $1=$ never, 2 = limited, 3 = partially, and $4=$ completely. The overall score and the score of all dimensions were calculated by summing all items' scores up and dividing them by the number of items. It ranges from 1 to 4 (22). The questionnaire was validated in Iran by Mirghafourvand et al and items were reduced from 33 to 36 based on Iranian culture. Cronbach alpha was reported as $\alpha=0.73$ in this study (20). 
In this study, reliability of functional status and maternal self-confidence questionnaires was confirmed by determining the internal consistency (Cronbach alpha $\alpha=0.77$ and $\alpha=0.84$, respectively) with conducting the test on 20 mothers in the postpartum period.

\section{Statistical Analyses}

Data were analyzed using SPSS 21. Normal distribution of data was examined using the Kolmogorov-Smirnov test. The demographic characteristic, functional status and maternal self-confidence were described using descriptive analysis, including frequency, percentage, mean and standard deviation. The Pearson test was used to investigate the association between maternal selfconfidence and the functional status. Furthermore, the independent $t$ test was used to determine the relationship between sex of newborn and mother's occupation with functional status and the one-way ANOVA test was used to determine the relationship between age, type of delivery, spouse's occupation, spouse and mother's education, income and marital satisfaction with functional status. Then, independent variables, with $P<0.05$ on bivariate tests inserted into the general linear model. This was done to control confounders and estimate the effect of each of the independent variables (maternal self-confidence, sex of newborn, spouse's occupation, spouse and mother's education) on the dependent variable (functional status) and determines the variance.

\section{Results}

In this study, nearly half of the women (41.9\%) were aged between 25-29. The average age of participants was $25.5 \pm 3.9$, and the majority of the women $(96.3 \%)$ were housewives. Half of their spouses (52.2\%) were selfemployed. Less than one-fifth of the women (11.8\%) had university education, and nearly half of their spouses (46.3\%) had elementary or secondary school educations. Regarding the income status, almost one-fifth of the women $(21.3 \%)$ stated that they had insufficient income. More than two-thirds of the women (74.3\%) were completely satisfied with their matrimonial life. Half of the participants $(52.2 \%)$ had baby girl, and 68 of the participants (50\%) had cesarean delivery (Table 1).

The mean (SD) of total functional status score was $2.2 \pm 0.4$, with achievable scores range from 1 to 4 . Regarding the dimensions of the functional status, the mean scores were household activities $2.2 \pm 0.7$, social and community activities $1.6 \pm 0.5$, infant care $3.3 \pm 0.6$ and self-care $2.0 \pm 0.3$, with achievable scores range from 1 to 4 . The mean score of maternal self-confidence $105.6 \pm 11.2$, with achievable scores range from 24 to 144 . Based on the Pearson test, there was a significantly positive and strong correlations between functional status and maternal selfconfidence $(r=0.271, P=0.001)$. Moreover, maternal self-confidence had statistically significant correlations with household activities $(r=0.176, P=0.040)$, social and
Table 1. Socio-Demographic Characteristics of Primiparous Women in Postpartum Period $(n=136)$

\begin{tabular}{|c|c|c|}
\hline Characteristics & & No. (\%) \\
\hline \multirow{4}{*}{ Age (y) } & $<25$ & $54(39.7)$ \\
\hline & $25-29$ & 57 (41.9) \\
\hline & $\geq 30$ & $25(18.4)$ \\
\hline & Mean (SD) & 25.5 (3.9) \\
\hline \multirow{3}{*}{ Type of delivery } & Vaginal delivery without episiotomy & 23 (16.9) \\
\hline & Vaginal delivery with episiotomy & $45(33.1)$ \\
\hline & Cesarean section & $68(50.0)$ \\
\hline \multirow{2}{*}{$\begin{array}{l}\text { Mother's } \\
\text { occupation }\end{array}$} & Housewife & $131(96.3)$ \\
\hline & $\begin{array}{l}\text { Working at home or outside the } \\
\text { home }\end{array}$ & $5(3.7)$ \\
\hline \multirow{3}{*}{$\begin{array}{l}\text { Spouse's } \\
\text { occupation }\end{array}$} & Worker or unemployed & $43(31.6)$ \\
\hline & Clerk & $22(16.2)$ \\
\hline & Self- unemployed & $71(52.2)$ \\
\hline \multirow{4}{*}{$\begin{array}{l}\text { Mother's } \\
\text { education }\end{array}$} & Secondary school & $46(33.8)$ \\
\hline & High school & 23 (16.9) \\
\hline & Diploma & $51(37.5)$ \\
\hline & University & $16(11.8)$ \\
\hline \multirow{3}{*}{$\begin{array}{l}\text { Spouse's } \\
\text { education }\end{array}$} & Elementary or secondary school & $63(46.3)$ \\
\hline & High school or diploma & $43(31.6)$ \\
\hline & University & $30(22.1)$ \\
\hline \multirow{3}{*}{ Income } & Completely enough & $19(14.0)$ \\
\hline & Somewhat enough & $88(64.7)$ \\
\hline & Not enough & $29(21.3)$ \\
\hline \multirow{2}{*}{ Sex of newborn } & Female & $71(52.2)$ \\
\hline & Male & $65(47.8)$ \\
\hline \multirow{3}{*}{$\begin{array}{l}\text { Marital } \\
\text { satisfaction }\end{array}$} & Completely & $101(74.3)$ \\
\hline & Somewhat & $33(24.3)$ \\
\hline & Not at all & $2(1.5)$ \\
\hline
\end{tabular}

community activities $(r=0.161, P=0.030)$, infant care $(r=0.246, P=0.004)$ and self-care $(r=0.212, P=0.013)$.

Based on the independent $t$ test and the one-way ANOVA, the functional status score was significantly related to the mother's education degree, spouse's education degree, spouse's occupation and infant's gender. These variables and the score of maternal self-confidence were inserted in the general linear model. Based on the moderated general linear model, the functional status was only related to maternal self-confidence $(P=0.004)$ (Table 2).

\section{Discussion}

The present study was conducted to determine the relationship between maternal self-confidence and functional status among primiparous women. The results of this study indicated that self-confidence influenced the functional status of women in the postpartum period. The majority of relevant studies investigated the relationships of factors influencing functional status. However, fewer studies were carried out on the relationship between maternal self-confidence and functional status. Nevertheless, McVeigh conducted a study on the 
Table 2. Association Between Functional Status and its Subscales With Maternal Self-confidence in Primiparous Women in the Postpartum Period $(n=136)$

\begin{tabular}{|c|c|c|c|}
\hline Variables & Mean (SD) & Achievable Score & Correlation With Maternal Self-Confidence, $r(P)^{a}$ \\
\hline Functional status score & $2.2(0.4)$ & $1-4$ & $0.271(0.001)$ \\
\hline Household activities & $2.2(0.7)$ & $1-4$ & $0.176(0.040)$ \\
\hline Social and community activities & $1.6(0.5)$ & $1-4$ & $0.161(0.030)$ \\
\hline Infant care activities & $3.3(0.6)$ & $1-4$ & $0.246(0.004)$ \\
\hline Self-care activities & $2.0(0.3)$ & $1-4$ & $0.212(0.013)$ \\
\hline Maternal self-confidence score & $105.6(11.2)$ & $24-144$ & - \\
\hline
\end{tabular}

Abbreviation: SD, standard deviation.

a Pearson correlation.

relationship between functional status after child birth, self-confidence, social support and anxiety in Australia. The results of this study indicated that women with higher levels of self-confidence and lower levels of anxiety could adapt to their maternal roles faster. It also showed that self-confidence, maternal anxiety, maternal satisfaction, the number of deliveries and sleep pattern influenced the functional status significantly. Moreover, the women with higher levels of self-confidence had higher mean scores in functional status, household responsibilities, social and community activities, infant care and self-care (23). These results are consistent with the results of the present study. However, the above mentioned study is different in terms of the time of collecting postpartum data and the tools used to evaluate maternal self-confidence.

According to the present study results regarding the dimensions of functional status, the highest mean score came from infant care and the lowest mean score came from social and community activities in the second week after the delivery, a fact which is consistent with the majority of previous studies. Norhayati et al conducted a study on the functional status of women with or without postpartum morbidity in Malaysia and McVeigh, carried out a study on the relationship between satisfaction with social support and functional status in Australia. Their results are consistent with the present study results. The highest mean score came from infant care, whereas the lowest mean score came from social and community activities (14,24).

Based on the results of the present study, there were no significant relationships between participants' demographics and postpartum functional status. Ahn and Youngblut conducted a study on the health status predictors of women in the first three months after the delivery. They highlighted that the mother's age, income status and social support were related to the functional status in the first 6 weeks after the delivery and in the third postpartum month, feeling of competence, mother's age and income status were related to the functional status. These are contrary to the present study results because the present study did not prove that functional status was related to the mother's age and income status (25). Posmontier by comparing the functional status of depressed women with that of the healthy ones in the postpartum period in the northeast of America, indicated that depressed women gained lower scores in self-care, social and community and household responsibilities in the postpartum period. However, the 2 groups were no different in infant care. Moreover, the number of deliveries, social support, maternal and neonatal complications and the type of delivery were related to the functional status. This study is contrary to the current study because there were no relationships between the type of delivery and the postpartum functional status in the current study (15). Participants' cultural differences can be deemed as a possible reason for results inconsistency of the above mentioned studies with current study. Tulman et al intending to describe the functional status of employed and unemployed women, indicated that these 2 groups were not significantly different from each other in the first postpartum 6 months in terms of functional status, household responsibilities, social and community activities, infant care and self-care. These are consistent with the results of the present study, according to which the mother's occupation and the postpartum functional status were not related (26).

\section{Limitations}

It should be noted that because of the cross-sectional nature of our study, the relationship observed between the functional status and the self-confidence cannot be interpreted as causal. On the other hand, the samples were only taken from urban centers and also included women without any complications of pregnancy and childbirth, a fact which may reduce the study generalize ability. Therefore, it is recommended that a similar study should be conducted on rural women and women with such complications.

\section{Conclusion}

The study results specified that maternal self-confidence influenced the functional status among women in the postpartum period. If maternal self-confidence level increases in the postpartum period, the functional status improves. Therefore, policy makers and employees should evaluate the maternal self-confidence levels in the postpartum period in order to improve the functional status among women. Consequently, the mother and 
child's health can be improved in this period.

\section{Ethical Issues}

The study was approved in the Ethics Committee of Tabriz University of Medical Sciences (No. TBZMED. REC.1394.547).

\section{Conflict of Interests}

The authors declare no conflict of interests.

\section{Financial Support}

The Deputy of Research of Tabriz University of Medical Sciences supported the study.

\section{Acknowledgments}

The authors would like to thank the Research Deputy, Faculty of Nursing and Midwifery, and Student Research Committee of Tabriz University of Medical Sciences, as well as participants and Tabriz health care personnel.

\section{References}

1. World Health Organization. WHO recommendations on postnatal care of the mother and newborn. Geneva: World Health Organization; 2013.

2. Gjerdingen DK, Froberg DG, Chaloner KM, McGovern PM. Changes in women's physical health during the first postpartum year. Arch Fam Med. 1993;2(3):277-283.

3. Ruchala PL, James DC. Social support, knowledge of infant development, and maternal confidence among adolescent and adult mothers. J Obstet Gynecol Neonatal Nurs. 1997;26(6):685-689. doi: 10.1111/j.1552-6909.1997. tb02743.x.

4. Lugina HI, Christensson K, Massawe S, Nystrom L, Lindmark G. Change in maternal concerns during the 6 weeks postpartum period: a study of primaparous mothers in Dar es Salaam, Tanzania. J Midwifery Womens Health. 2001;46(4):248-257. doi: 10.1016/S1526-9523(01)00133-7.

5. Badr LK. Further psychometric testing and use of the Maternal Confidence Questionnaire. Issues Compr Pediatr Nurs. 2005;28(3):163-74. doi: 10.1080/01460860500227572.

6. Jones TL, Prinz RJ. Potential roles of parental self-efficacy in parent and child adjustment: a review. Clin Psychol Rev. 2005;25(3):341-63. doi: 10.1016/j.cpr.2004.12.004.

7. Kuo CP, Chuang HL, Lee SH, Liao WC, Chang LY, Lee MC. Parenting confidence and needs for parents of newborns in Taiwan. Iran J Pediatr 2012;22(2):177-84.

8. Liu CC, Chen YC, Yeh YP, Hsieh YS. Effects of maternal confidence and competence on maternal parenting stress in newborn care. J Adv Nurs. 2012;68(4):908-18. doi: 10.1111/j.1365-2648.2011.05796.x.

9. Fowles ER, Horowitz JA. Clinical assessment of mothering during infancy. J Obstet Gynecol Neonatal Nurs 2006;35(5):662-670. doi: 10.1111/j.1552-6909.2006.00090.x.

10. Nelson AM. Transition to motherhood. J Obstet Gynecol Neonatal Nurs. 2003;32(4):465-77.

11. Kline CR, Martin DP, Deyo RA. Health consequences of pregnancy and childbirth as perceived by women and clinicians. Obstet Gynecol 1998;92(5):842-848. doi: 10.1016/ S0091-2182(99)00010-5.

12. Cox BE, Smith EC. The mother's self-esteem after a cesarean section. MCN Am J Matern Child Nurs. 1982;7(5):309-314.

13. Tulman L, Fawcett J. Return of functional ability after childbirth. Nurs Res. 1988;37(2):77-81. doi: 10.1097/00006199-198803000-00004.

14. McVeigh CA. Investigating the relationship between satisfaction with social support and functional status after childbirth. MCN Am J Matern Child Nurs. 2000;25(1):2530.

15. Posmontier B. Functional status outcomes in mothers with and without postpartum depression. J Midwifery Womens Health. 2008;53(4):310-318. doi: 10.1016/j. jmwh.2008.02.016.

16. Barkin JL, Wisner KL, Bromberger JT, Beach SR, Wisniewski SR. Assessment of functioning in new mothers. J Womens Health. 2010;19(8):1493-9. doi: 10.1089/jwh.2009.1864.

17. Goto A, Nguyen QV, Nguyen TT, et al. Associations of psychosocial factors with maternal confidence among Japanese and Vietnamese mothers. J Child Fam Stud. 2010;19(1):118-27. doi: 10.1007/s10826-009-9291-9.

18. Barkin JL, Wisner KL, Bromberger JT, Beach SR, Terry MA, Wisniewski SR. Development of the Barkin Index of Maternal Functioning. J Womens Health. 2010;19(12):22392246. doi: 10.1089/jwh.2009.1893.

19. Jaafarnejad F, Azmoude E, Mazlom R, Reyhani T. Effect of self-efficacy-based training on maternal self-confidence of primiparous women in the infants care. IJOGI 2014;17(104):18-28. doi: 10.22038/ijogi.2014.3021.

20. Mirghafourvand M, Mohammad-Alizadeh-Charandabi S, Asghari Jafarabadi M, Soltanpour S. Psychometric properties of the Iranian version of the inventory of functional status after childbirth (IFSAC). Iran Red Crescent Med J. 2017;19(5):e30210. doi:10.5812/ircmj.30210.

21. Reck C, Noe D, Gerstenlauer J, Stehle E. Effects of postpartum anxiety disorders and depression on maternal self-confidence. Infant Behav Dev. 2012;35(2):264-272. doi: 10.1016/j.infbeh.2011.12.005.

22. Fawcett J, Tulman L, Myers ST. Development of the inventory of functional status after childbirth. J Nurse Midwifery. 1988;33(6):252-260. doi:10.1016/0091-2182(88)90080-8.

23. McVeigh C. Social recovery after childbirth: an investigation into the relationship between functional status after childbirth, self-esteem, social support and anxiety [dissertation]. Wollongong: Department of Nursing, University of Wollongong; 1995.

24. Norhayati MN, Nik Hazlina NH, Aniza AA. Functional status of women with and without severe maternal morbidity: A prospective cohort study. Women Birth. 2016;29(5):443-449. doi: 10.1016/j.wombi.2016.02.002.

25. Ahn S, Youngblut JM. Predictors of Women's Postpartum Health Status in the First 3 Months After Childbirth. Asian Nurs Res (Korean Soc Nurs Sci). 2007;1(2):136-46. doi: 10.1016/S1976-1317(08)60016-X.

26. Tulman L, Fawcett J, Groblewski L, Silverman L. Changes in functional status after childbirth. Nurs Res. 1990;39(2):705. doi: 10.1097/00006199-199003000-00002.

Copyright $\odot 2017$ The Author (s); This is an open-access article distributed under the terms of the Creative Commons Attribution License (http://creativecommons.org/licenses/by/4.0), which permits unrestricted use, distribution, and reproduction in any medium, provided the original work is properly cited. 